\title{
Nanoparticle Albumin-Bound Rapamycin
}

National Cancer Institute

\section{Source}

National Cancer Institute. Nanoparticle Albumin-Bound Rapamycin. NCI Thesaurus. Code C74065.

The macrolide antibiotic rapamycin bound to nanoparticle albumin with

immunosuppressant (see sirolimus) and potential antiangiog enic and antineoplastic activities. Rapamycin binds to the immunophilin FK Binding Protein-12 (FKBP-12) to generate a complex that binds to and inhibits the activation of the mammalian Target Of Rapamycin (mTOR), a key regulatory kinase. In turn, inhibition of mTOR may result in the inhibition of the phosphatidylinositol 3 (PI-3) kinase/Akt pathway and vascular endothelial cell growth factor (VEGF) secretion, which may result in decreased tumor cell proliferation and tumor angiogenesis. The binding of water-insoluble rapamycin to nanoparticle albumin permits the albumin-mediated endocytosis of rapamycin by tumor cells and endothelial cells. 